\title{
IDENTIFICAÇÃO DE VARIANTES DO ONCOGENE E7 DO PAPILOMAVÍRUS HUMANO 16 EM AMOSTRAS CLÍNICAS DO NORDESTE DO BRASIL
}

\author{
R. C. P. LIMA ${ }^{1}$, M. N. CORDEIRO ${ }^{1}$, R. C. O. SILVA ${ }^{1}$, D. L. SANTOS ${ }^{1}$, M. R. B. \\ JÚNIOR $^{1}$, A.P.F. CAMPOS ${ }^{1}$, A.J.D. DA SILVA ${ }^{1}$, A. P. A. D. GURGEL ${ }^{2}$, M. V. A. \\ BATISTA $^{3}$, B. S. CHAGAS ${ }^{1}$ e A. C. FREITAS $^{1}$
}

${ }^{1}$ Universidade Federal de Pernambuco, Departamento de Genética, Laboratório de Estudos Moleculares e Terapia Experimental

${ }^{2}$ Universidade Federal da Paraíba, Departamento de Engenharia e Meio ambiente

${ }^{3}$ Universidade Federal de Sergipe, Departamento de Biologia

E-mail para contato: ritajpbio@gmail.com; acf_ufpe@yahoo.com.br

\begin{abstract}
RESUMO - Câncer cervical é causado pela infecção persistente pelo papilomavírus humano (HPV) de alto risco. A oncogenicidade do HPV está fortemente associada aos tipos virais e suas variantes, cujos polimorfismos em oncogenes virais podem estar envolvidos no risco de progressão maligna. A presença de polimorfismos pode levar à alteração da função biológica com consequências clínicas, além de prejudicar o controle do ciclo celular mediado por pRB. Em pacientes do Nordeste do Brasil, nosso estudo descreveu a presença de tipos de HPV e variantes de amostras cervicais por técnicas de $P C R$ e sequenciamento, além de identificar polimorfismos no gene E7 de HPV-16. O $H P V-16$ foi encontrado como o tipo mais prevalente, seguido por HPV-31 e HPV-58. Entre as variantes do HPV-16, as linhagens $C$ e D foram detectadas principalmente em lesões cervicais de alto grau. Ainda, identificamos quatro polimorfismos do gene E7 do HPV-16, um polimorfismo não-sinônimo e três sinônimos. Novas mutações adaptativas podem levar o vírus a evadir o sistema imunológico do hospedeiro e aumentar a patogenicidade. Estes resultados adicionam dados importantes para os estudos sobre a variabilidade de E7, o que poderia contribuir para uma melhor compreensão da diversidade e infecção do HPV.
\end{abstract}

Palavras chave: Polimorfismo, oncogene E7, HPV-16

ABSTRACT - Cervical cancer is caused by persistent high-risk human papillomavirus (HPV) infection. HPV oncogenicity is strongly associated with viral types and their variants, whose polymorphisms in viral oncogenes are involved in the risk of malignant progression. The presence of polymorphisms can be used in biological function with clinical consequences. In addition to impairing the control of the cell cycle mediated by pRB. In patients from Northeastern Brazil, our study described the presence of HPV types and variants of cervical samples by PCR and sequencing technique, as well as identifying polymorphisms, no HPV-16 E7 gene. HPV-16 was found to be the most prevalent type, followed by HPV-31 and HPV-58. Among the HPV-16 variants, such as C and D strains were detected mainly in high-grade cervical lesions. In addition, we identified four polymorphisms of the HPV-16 E7 gene. A non-synonymous polymorphism and three 
problems. New adaptive mutations can cause the virus to bypass the host's immune system and increase pathogenicity. These results added important data for the studies on a variability of E7, which could contribute to a better understanding of the diversity and infection of $H P V$.

Keywords: Polymorphisms, E7 oncogene, HPV-16;

\section{INTRODUÇÃO}

A infecção persistente por HPVs de alto risco é o principal fator predisponente para a formação de neoplasia cervical de alto grau (Rosita et al., 2012). Os tipos de HPV são distribuídos entre cinco gêneros: Alphapapillomavirus, Betapapillomavirus, Gammapapillomavirus, Mupapillomavirus e Nupapillomavirus (Bernard et al., 2010). Apenas o gênero Alphapapillomavirus contém tipos de HPV de alto risco, incluindo 16, 18, 31, 33, $35,39,45,51,52,56,58,59,68,73$ e 82. As variantes de HPV são classificadas em linhagens e sub-linhagens baseadas na análise da sequência do genoma (Chen et al., 2011). A análise filogenética HPV-16 agrupou as variantes do HPV-16 foram em quatro linhagens (A, B, C e D) e nove sublinhagens (Burk et al., 2013). Vários estudos correlacionaram variantes C e D do HPV-16 com infecção viral persistente, que podem ser seguidas por resultados de lesões malignas (Burk et al., 2013; Gurgel et al., 2013). Além das variantes funcionais com oncogenicidade diferencial e imunogenicidade, os polimorfismos de nucleotídeos únicos (SNPs) podem estar envolvidos no potencial de integração específico da variante (Jackson et al., 2016).

\section{MATERIAIS E MÉTODOS}

Foram coletas 318 amostras de escovados cervicais na Unidade de Ginecologia do Hospital Clínico $(\mathrm{n}=81)$ e Hospital Universitário Oswaldo Cruz $(\mathrm{n}=156)$ em Recife, Estado de Pernambuco e no Centro de Atenção Integral para Saúde da Mulher $(n=81)$ em Aracajú, Estado de Sergipe. Este estudo foi aprovado pelo Comitê de Ética e Pesquisa da Universidade Federal de Pernambuco (CEP / CCS / UFPE 491/11), e Complexo Hospitalar Oswaldo Cruz (HUOC / PROCAPE 64/2010).

As células cervicais tiveram seu DNA extraído e a detecção do HPV foi realizado por Polymerase Chain Reaction (PCR) usando iniciadores MY09 / MY11 (Manos et al., 1989). As amostras positivas para HPV foram genotipadas com iniciadores específicos para cada tipo viral. Cinquenta e seis amostras cervicais positivas para HPV-16 foram analisadas adicionalmente por amplificação da sequência E7 por PCR. As sequências de nucleotídeos foram determinadas por sequenciamento.

As sequências foram alinhadas com a sequência de referência HPV-16 E7 (GenBank Número de acesso: K02718) usando a ferramenta de alinhamento BLAST( Altschul et al., 1990) para identificação dos polimorfismos. As árvores filogenéticas foram construídas usando o método de Máxima probabilidade com o modelo evolutivo Kimura 2-Parameter e o método SPR heuristic usando o software MEGA versão 5.2 (Tamura et al., 2011).

\section{RESULTADOS E DISCUSSÃO}

Um total de 318 amostras cervicais foram rastreadas com iniciadores de consenso 
L1. $225(70,8 \%)$ destas amostras testadas foram positivas para o DNA do HPV. Outros genótipos com iniciadores específicos revelaram que 56 (24,9\%), $37(16,4 \%)$ e 12 (5,3\%) amostras foram positivas para HPV-16, HPV-31 e HPV-58, respectivamente. Foram detectadas várias amostras que mostram que a presença simultânea de HPV-16 / HPV-31 HPV-16 / HPV-58, HPV-16 / HPV-31 / HPV-58 foi em 48 (21,3\%), 6 (2,6\%) e 5 (2,2\%) amostras, respectivamente. A genotipagem do HPV não foi realizada em sessenta e uma amostras.

As amostras positivas de HPV-16 foram submetidas a amplificação e sequenciamento do gene E7. No entanto, 32 amostras foram excluídas porque não produziram uma sequência confiável. Assim, 24 amostras foram analisadas quanto à presença de polimorfismos no gene E7 de HPV-16. Entre esses espécimes, 18, 4 e 2 amostras foram de pacientes com HSIL (75\%), LSIL $(16,7 \%)$ e câncer cervical $(8,3 \%)$, respectivamente.

A análise comparativa do gene E7 com a sequência de referência do HPV-16 revelou que oito isolados $(33,3 \%)$ eram variantes E7 de HPV-16. Quatro mutações diferentes foram encontradas nesses isolados. Uma mutação não sinônima (A647G) foi descrita tendo a alteração de aminoácidos N29S. As outras três alterações foram mutações sinônimas nas posições 732, 789 e 795 (Figura 1). Foram avaliadas as relações evolutivas entre as sequências E7 de HPV-16. A árvore filogenética mostrou um agrupamento baseado em linhagens dos isolados, que agrupa as variantes E7 de HPV-16 em quatro linhagens diferentes (Figura 2). A árvore filogenética apresenta clusters parcialmente bem suportados, possibilitando a genotipagem das variantes HPV-16. Quinze isolados podem ser classificados como linhagem A e três como linhagem B, C ou D, respectivamente.

Figura 1: Alterações de nucleótidos e aminoácidos no gene E7 dos isolados de HPV-16 identificados neste estudo com base na sequência de referência (K02718).

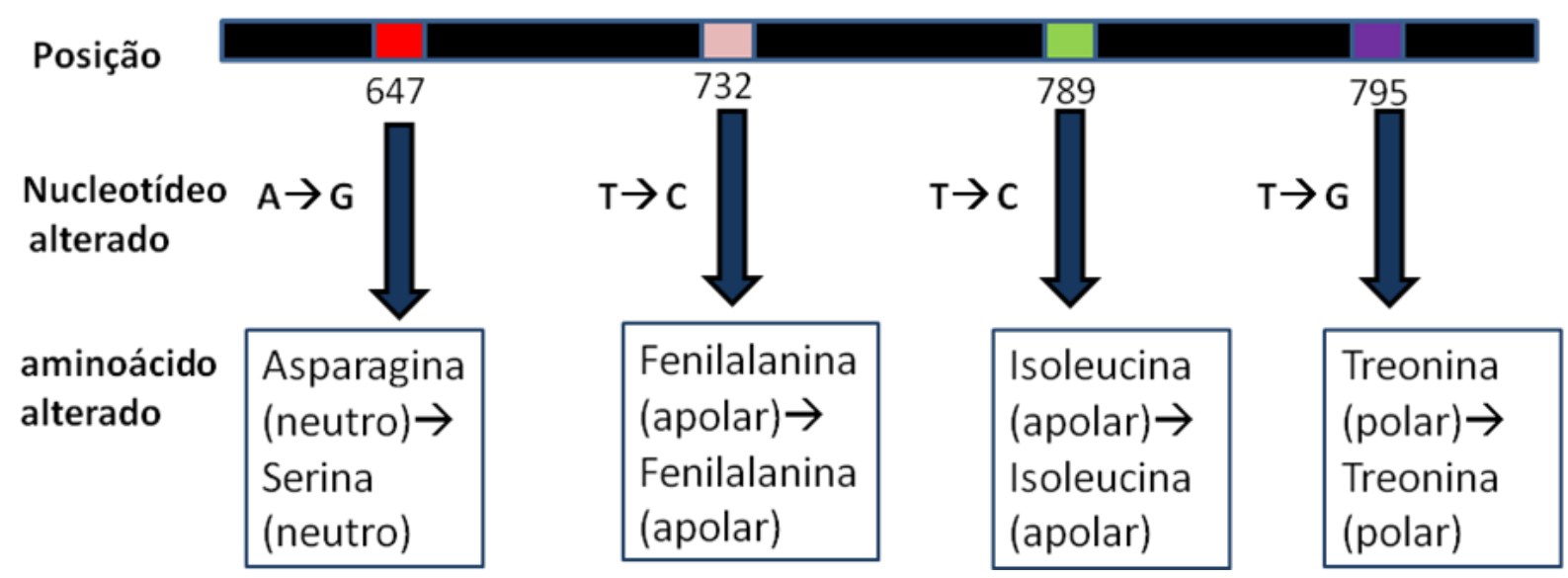


Figura 2 - Árvore filogenética de máxima verossimilhança das variantes de HPV-16 com base no gene E7. Quatro agrupamentos foram identificados como linhagens A, B, C e D.

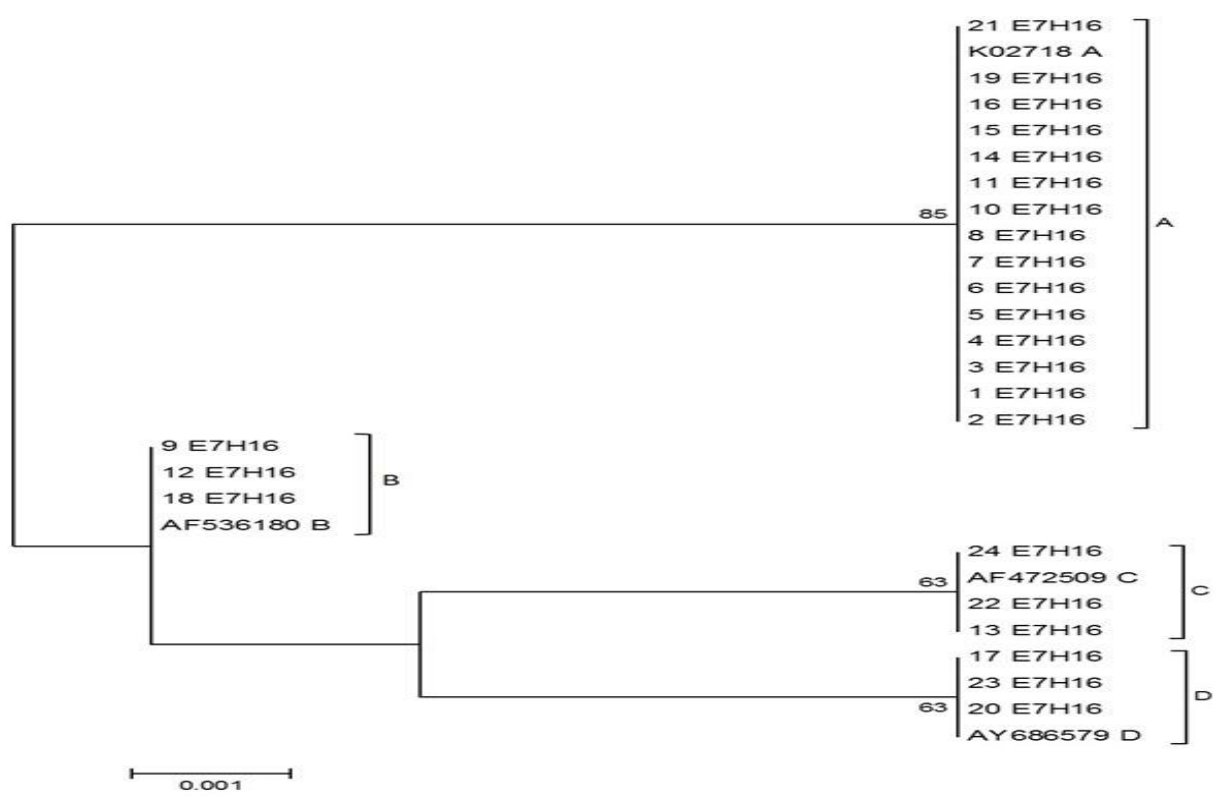

\section{CONCLUSÃO}

Novas mutações adaptativas podem levar o vírus a evadir o sistema imunológico do hospedeiro e a aumentar a patogenicidade. Esses resultados adicionam dados importantes sobre a variabilidade E7, o que poderia contribuir para uma melhor compreensão da diversidade e infecção do HPV.

\section{REFERÊNCIAS}

Altschul SF, Gish W, Miller W, Myers EW, Lipman DJ. 1990. Basic local alignment search tool. J Mol Biol 215:403-410. Bernard HU, Burk RD, Chen Z, Doorslaer KV, Hausen HZ, Villiers EM. Classification of Papillomaviruses (PVs) Based on 189 PV Types and Proposal of Taxonomic Amendments. Virology 401:70-79. 2010.

Burk RD, Harari A, Chen Z. Human papillomavirus genome variants. Virology 445:232243. 2013.

Chen Z, Schiffman M, Herrero R, Desalle R, Anastos K, Segondy M, Sahasrabuddhe VV, Gravitts PE, Hsing AW, Burk RD. Evolution and Taxonomic Classification of Human Papillomavirus 16 ( HPV16 ) -Related Variant Genomes: HPV31, HPV33, HPV35, HPV52, HPV58 and HPV67. PLoS ONE 6:e20183. 2011.

Gurgel AP, Chagas BS, Amaral CMM, Albuquerque EMB, Serra IGSS, Silva Neto JC, Muniz MTC, Freitas AC. Prevalence and Genetic Variability in Capsid L1 Gene of Rare Human Papillomaviruses (HPV) Found in Cervical Lesions of Women from North-East Brazil. BioMed Research International, Article ID 546354, 7 pages. 2013. 
Manos, M.M; Ting,Y; Wright, DK; Lewis, AJ; Broker, TR; Wolinsky, SM. Use of polymerase chain reaction amplification for the detection of genital human papillomaviruses, Cancer Cells . 209-213. 1989.

Rositch AF, Burke, AE, Viscidi RP, Silver ML, Chang K, Gravitt P. Contributions of recent and past sexual partnerships on incident human papillomavirus detection: acquisition and reactivation in older women. Cancer Res. 72: 6183-6190. 2012.

Tamura K, Peterson D, Peterson N, Stecher G, Nei M, Kumar S. MEGA5 : Molecular Evolutionary Genetics Analysis Using Maximum Likelihood, Evolutionary Distance, and Maximum Parsimony Methods. Mol Bio Evol 28:2731-2739. 2011.

\section{AGRADECIMENTOS}

Conselho Nacional de Desenvolvimento Científico e Tecnológico (CNPq), Fundação de Amparo à Ciência e Tecnologia de Pernambuco (FACEPE), Coordenação de Aperfeiçoamento de Pessoal de Nível Superior (CAPES), Universidade Federal de Pernambuco. 